This item was submitted to Loughborough's Research Repository by the author.

Items in Figshare are protected by copyright, with all rights reserved, unless otherwise indicated.

\title{
Use of wall suction in half model wind tunnel testing
}

PLEASE CITE THE PUBLISHED VERSION

PUBLISHER

American Institute of Aeronautics and Astronautics (AIAA) / ( The authors

VERSION

AM (Accepted Manuscript)

LICENCE

CC BY-NC-ND 4.0

REPOSITORY RECORD

Mailk, Abdullah, and Peter M. Render. 2010. "Use of Wall Suction in Half Model Wind Tunnel Testing". figshare. https://hdl.handle.net/2134/6414. 
This item was submitted to Loughborough's Institutional Repository (https://dspace.lboro.ac.uk/) by the author and is made available under the following Creative Commons Licence conditions.

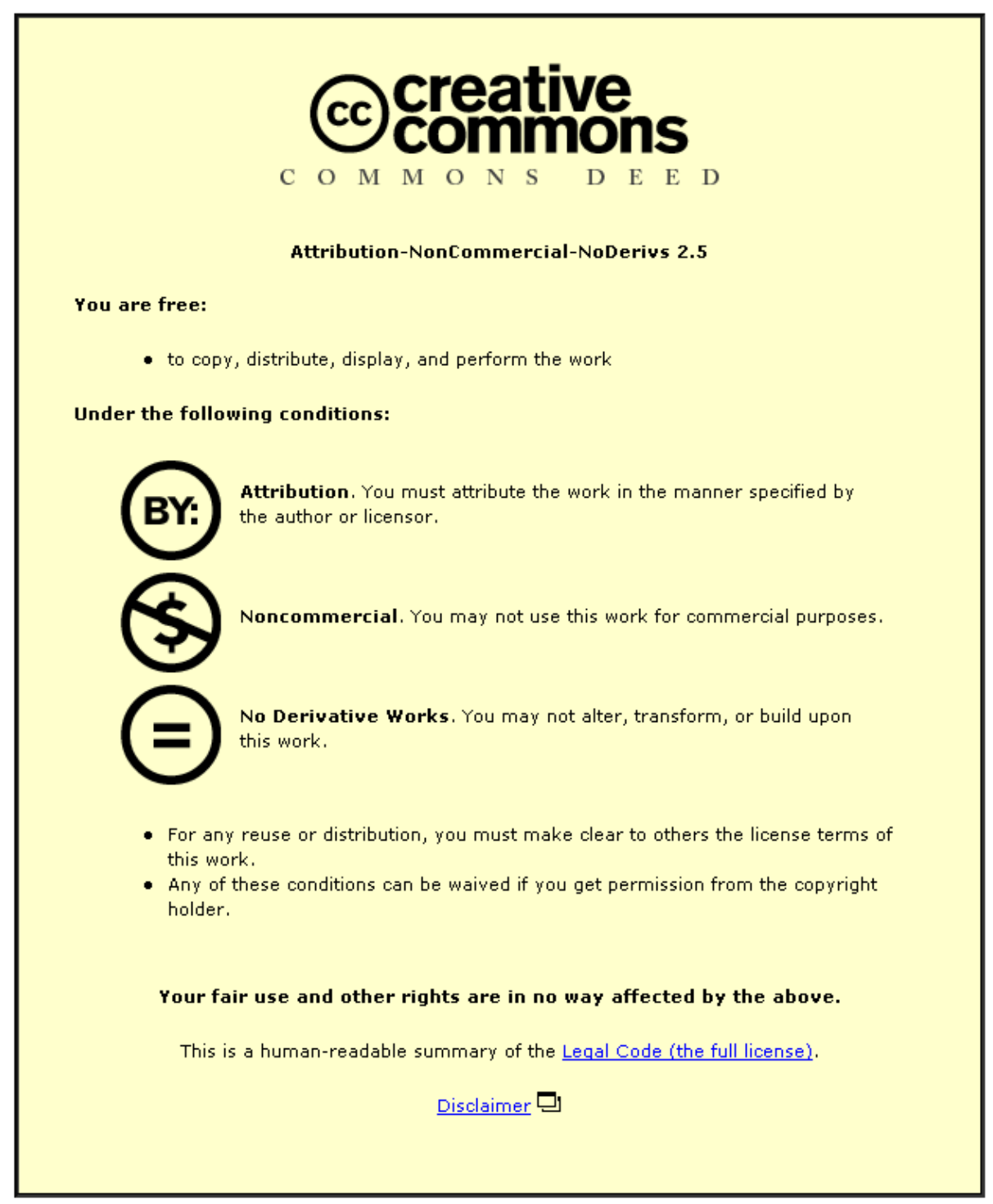

For the full text of this licence, please go to: http://creativecommons.org/licenses/by-nc-nd/2.5/ 


\title{
Use of Wall Suction in Half Model Wind Tunnel Testing
}

\author{
A. Malik ${ }^{1}$ and P.M. Render ${ }^{2}$ \\ Loughborough University, Loughborough, Leicestershire, LE11 3TU, United Kingdom
}

\begin{abstract}
The half model wind tunnel technique suffers from aerodynamic loses due to the interaction of the tunnel wall boundary layer with the flow over the model and the formation of a horseshoe vortex in the model-floor junction. The vortex is believed to contribute to the degradation of the half model aerodynamic performance. An attempt was made to reduce the aerodynamics losses by modifying the junction horseshoe vortex through the use of localized suction just upstream of the model leading edge. Wind tunnel tests on a rectangular and untwisted, wing only, modified LS(1)-0413 half model were conducted at Reynolds numbers of $0.44 \times 10^{6}, 0.88 \times 10^{6}$ and $1 \times 10^{6}$. Without suction the force and moment balance measurements of the half model showed the anticipated deviation from full model values, e.g. lower lift curve slope and higher drag values. Effects of localized suction were limited to Reynolds number of $0.44 \times 10^{6}$ and improvements were seen only near stall angles of attack. Flow visualization for the no suction case showed that a horseshoe vortex did not exist over much of the incidence range for this particular model and hence there was little room for suction to effect junction flow. Near stall, suction removed the horseshoe vortex around the upper surface of the model and significantly reduced flow separations occurring in the model-floor junction, leading to the improved stall characteristics.
\end{abstract}

\section{Nomenclature}

$=$ volume flow rate

$=$ air speed

$=$ axis parallel to the flow direction

$=$ axis along span of model

$=$ axis normal to the wing chord

\section{Introduction}

$\mathrm{T}$ he major advantage of half model testing compared to full model, is the achievement of higher Reynolds numbers in a given wind tunnel test section. The half model technique has some inherent short comings due to the presence of the wind tunnel wall boundary layer which adversely affects the results in a number of ways. The wall boundary layer modifies the freestream velocity approaching the model close to the wall, and its displacement thickness reduces the model's effective aspect ratio ${ }^{1}$. Also, the wall boundary layer can separate at the model's leading edge forming a horseshoe vortex in the junction between the floor and the model. These effects combine to result in the following well known discrepancies in half model aerodynamic behavior when compared to a full model:

Reduced lift curve slope ${ }^{2,3}$,

Early stall particularly at lower Reynolds numbers ${ }^{4}$,

Increase in the zero lift incidence ${ }^{2}$,

Increased drag values ${ }^{2,3}$,

The tendency for boundary layer separation and stall near the wing root ${ }^{3,4}$,

\footnotetext{
${ }^{1}$ Research Student, Department of Aeronautical and Automotive Engineering.

${ }^{2}$ Senior Lecturer, Department of Aeronautical and Automotive Engineering. Senior Member AIAA.

1

American Institute of Aeronautics and Astronautics
} 
The presence of the horseshoe vortex at the leading edge of a half model is well known, but few efforts have been made to improve half model tests results by modifying this vortex. Bippes ${ }^{5}$ was the first to have proposed localized suction upstream the model leading edge to avoid boundary layer separation on the tunnel floor. Philips ${ }^{6}$, Barberis $^{7}$ and Johnson ${ }^{8}$, showed that the horseshoe vortex could be removed from the junction region by the use of localized suction just upstream of the model leading edge. However, none of these studies investigated how removing the horseshoe vortex affected the aerodynamic performance of the half model. The potential of localized suction seemed quite promising and it was decided to evaluate its effectiveness as a practical wind tunnel technique for improving half model results. Employing localized suction to eliminate the horseshoe vortex has the benefit over passive devices in that it gives the potential to vary suction and so adapt the technique for different half model geometries.

\section{Background}

When the approaching wall boundary layer is unable to overcome the adverse pressure gradient created by an obstruction such as a wing, it eventually separates from the wall as shown in Fig. 1 (adapted from reference 9). This separation creates a reverse flow region in front of the wing and interacts with the stream wise flow to form a horseshoe vortex. The vortex wraps around the wing in the junction region and is believed to contribute to the aerodynamic losses in the junction area. A detailed description of the horseshoe vortex and the associated separation can be found from Eckerle ${ }^{10}$ and Johnston ${ }^{11}$.

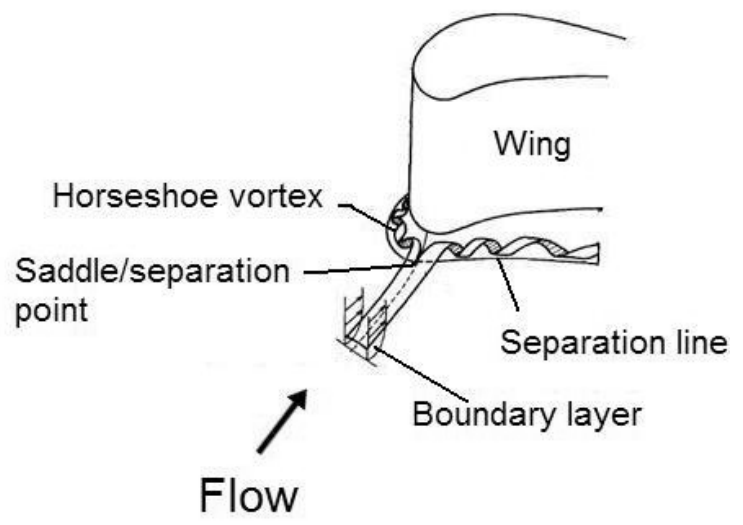

Fig. 1. Formation of horseshoe vortex in leading edge junction region

\section{Test Arrangements and Model Description}

Half model tests have been conducted at Loughborough University in a low speed indraft wind tunnel. The tunnel has a closed working section of $1.9 \times 1.3 \mathrm{~m}$ and a length of $3.6 \mathrm{~m}$. The tunnel wall boundary layer thickness and displacement thickness at the centre of the turntable are $60 \mathrm{~mm}$ and $9.4 \mathrm{~mm}$, respectively at the tunnel speed (V) of $40 \mathrm{~m} / \mathrm{s}^{12}$. Turbulence intensity at the centre of the tunnel cross section is $0.15 \%{ }^{12}$. A righthanded coordinate system (as shown in Fig. 2) is used in the test section in which $\mathrm{X}$ is in the free steam direction, $\mathrm{Y}$ is along the wing span and $\mathrm{Z}$ in normal to the wing chord. The centre of the coordinate system coincides with the centre of the turntable as shown in Fig. 2. Below the turntable is an under-floor balance.

The model used was a rectangular untwisted half wing with a span of $950 \mathrm{~mm}$ and a chord of $315 \mathrm{~mm}$. The airfoil section was modified LS(1)-0413. The test arrangement is shown schematically in Fig. 3. Although the physical aspect ratio was 3.02 this was theoretically doubled by the tunnel floor which acted as a reflection plane. At a tunnel maximum speed of $45 \mathrm{~m} / \mathrm{s}$, a Reynolds number of $1 \times 10^{6}$ based on

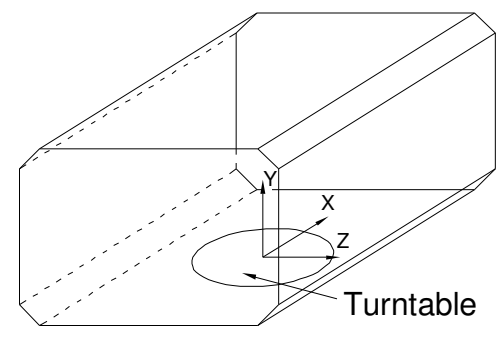

Flow

Fig. 2. Test section reference axis system 
airfoil chord was achieved. The model was mounted on to the under-floor balance with had a nominal accuracy of $\pm 0.0000712, \pm 0.0000297$ and \pm 0.0000577 for lift, drag and pitching moment coefficient, respectively at $45 \mathrm{~m} / \mathrm{s}$. The balance repeatability characteristics for tests repeated after six months showed a variation of better than \pm 0.00656 for lift coefficient. The variation seen in the drag coefficient was \pm 0.0004 . In the case of pitching moment coefficient a maximum shift of 0.001 was observed.

Balance measurements required a small gap to be left between the tunnel floor and the model. To minimize the possible effects of air leakage through the gap, the model extended below the tunnel floor. The extension was in turn surrounded by a box which had the effect of moving the main potential leakage path to between the box and the strut. During tunnel runs static pressure measurements within the box indicated negligible leakage flow.

Solid and wake blockage ${ }^{13}$ along with lift interference corrections ${ }^{14}$ were applied to balance measurements.

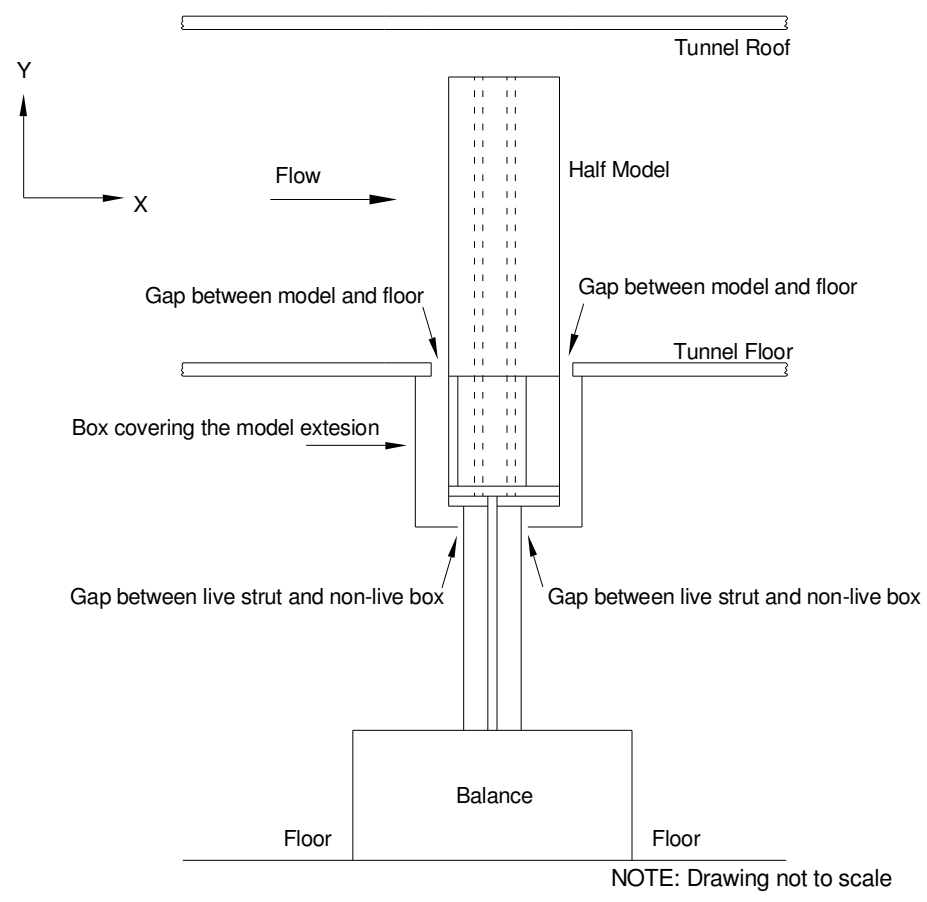

Fig. 3. Model setup for half model tests (side view)

\section{Test Datum Half Model Results Using the Tunnel Floor as the Reflection Plane}

Comparison of full span and half model force and moment data at a Reynolds number of 1 x $10^{6}$ is shown in Fig. 4 to Fig. 6. Full span ( $\mathrm{AR}=6$ ) data for a modified LS(1)-0413 was obtained by converting two dimensional airfoil data from reference 15 and using the aspect ratio corrections methods from reference 16 . This data is termed full span in the following discussion, and it represents the datum against which all of the half model data is compared.

As expected, compared with full span, the half model showed decreased lift curve slope and increased drag coefficient values. The lift curve slope obtained by curve fitting between -5.0 and 6.0 degrees was $0.0774 /$ degree for the half model compared to the full span value of $0.0815 /$ degree (Fig. 4). In addition, the zero lift incidence angle changed from -

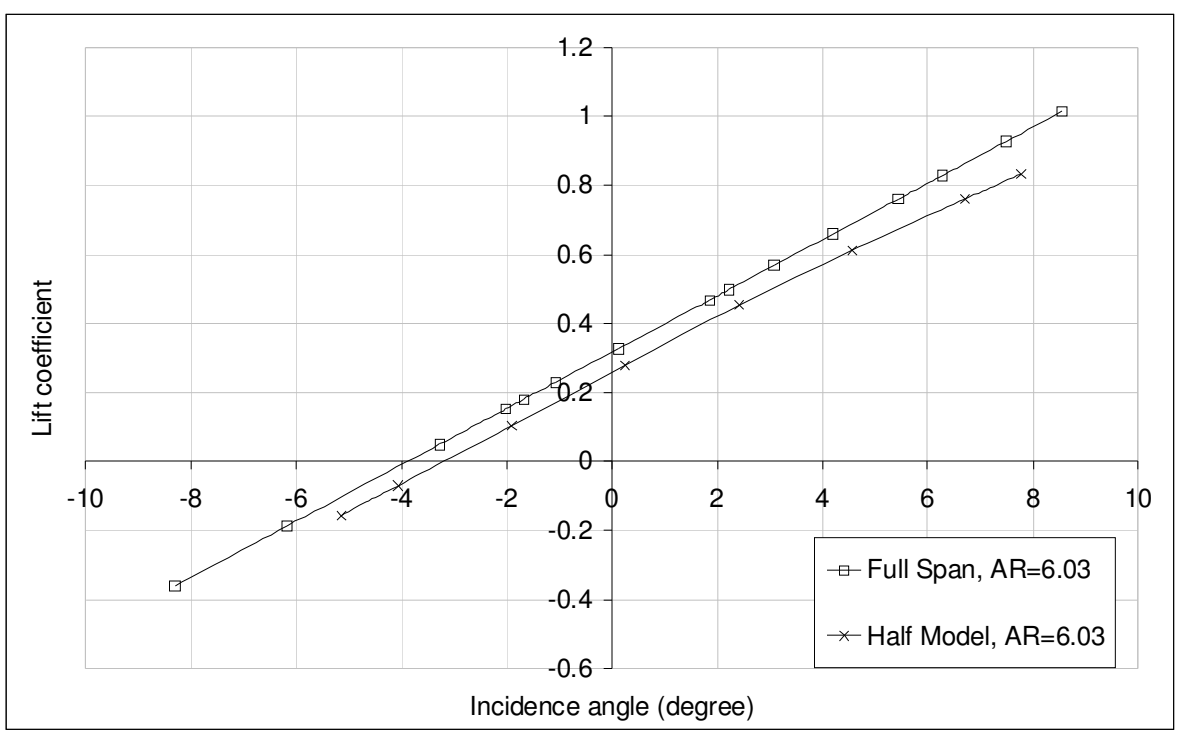

Fig. 4. Lift coefficient for full and half span models, Reynolds number $-1 \times 10^{6}$ 
3.9 degrees for full span to -3.2 for half span. Half model drag was increased throughout the incidence range, with a minimum drag coefficient of 0.0122 compared with 0.0089 for the full span (Fig. 5). Nose down pitching moment coefficient about the quarter chord for the half model reduced compared to the full span (Fig. 6).

Due to balance limitations it wasn't possible to take the half model up to stall at a Reynolds number of $1 \times 10^{6}$. The choice of Reynolds number was determined by the available full span data. The lack of stall information was not seen as an issue, because initially the focus of the investigation was on sub stall incidences.

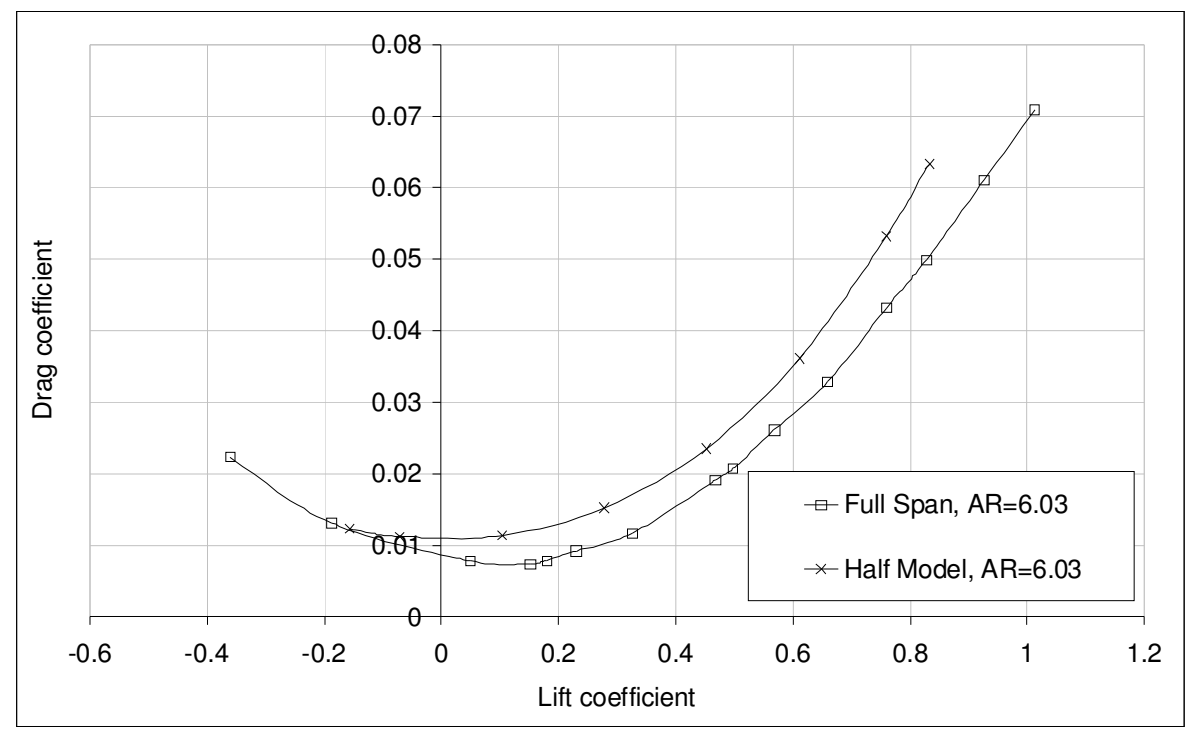

Fig. 5. Drag coefficient for full and half span models, Reynolds number $-1 \times 10^{6}$

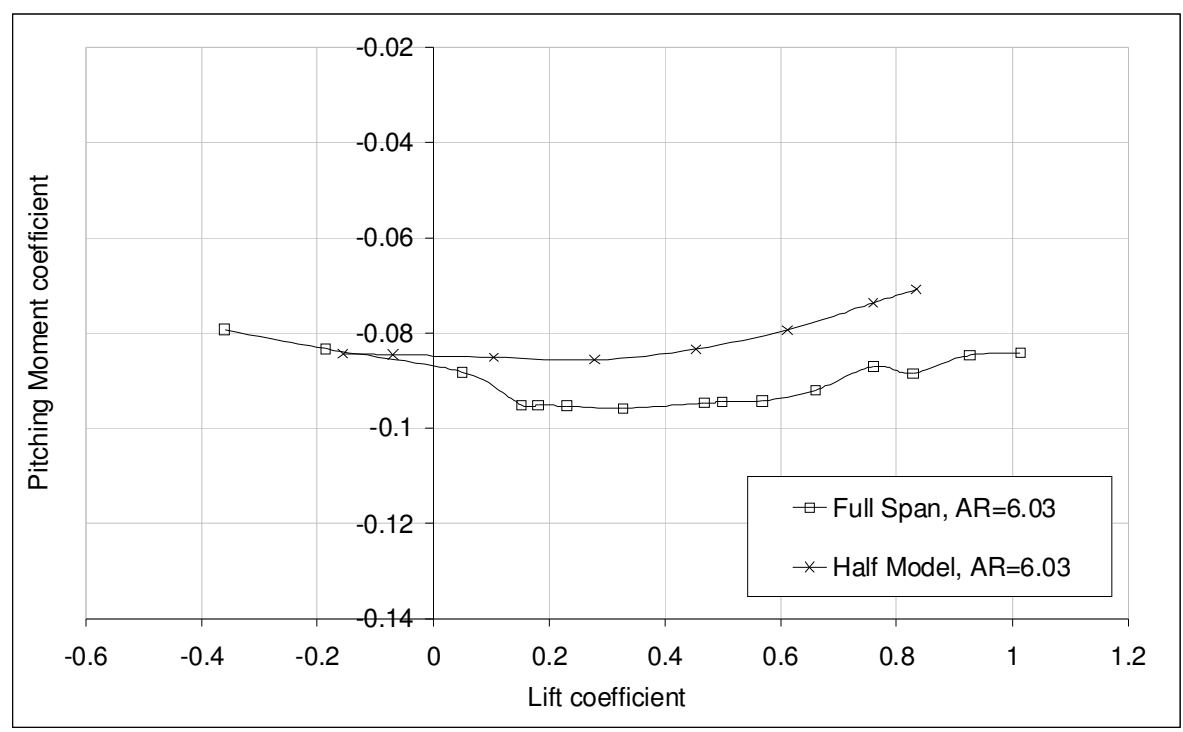

Fig. 6. Pitching moment coefficient for full and half span models, Reynolds number $-1 \times 10^{6}$

American Institute of Aeronautics and Astronautics 


\section{The Suction System}

The design of suction system was based on the work of Philips ${ }^{6}$, Barberis ${ }^{7}$ and Johnson ${ }^{8}$. The general arrangement of the suction system is shown in Fig. 7. The system was designed around an existing fan and the limited capabilities of the fan did not allow removal of sufficient boundary layer at a tunnel speed of $45 \mathrm{~m} / \mathrm{s}$. Hence the suction system was designed for a tunnel speed of $20 \mathrm{~m} / \mathrm{s}$. At the start of the suction system design process, the separation point for the model-floor junction was estimated using Fluent. These simulations predicted the saddle point $8 \mathrm{~mm}$ upstream of the model leading edge (on the lower surface side) for freestream velocity of $20 \mathrm{~m} / \mathrm{s}$. Based on Barberis ${ }^{7}$ experiments to eliminate the vortex with minimum suction rate, a slot had to be located between the separation point and the model leading edge, i.e. within $8 \mathrm{~mm}$. In the present experiment, locating a suction hole here was not practical for many reasons. Philips ${ }^{6}$ demonstrated that the horseshoe vortex could be removed using increased suction upstream of the separation point. Based on Philips ${ }^{, 6}$ findings the suction system was designed to be capable of removing 1.9 times and greater of the boundary layer volume flow rate over the width of the suction hole.

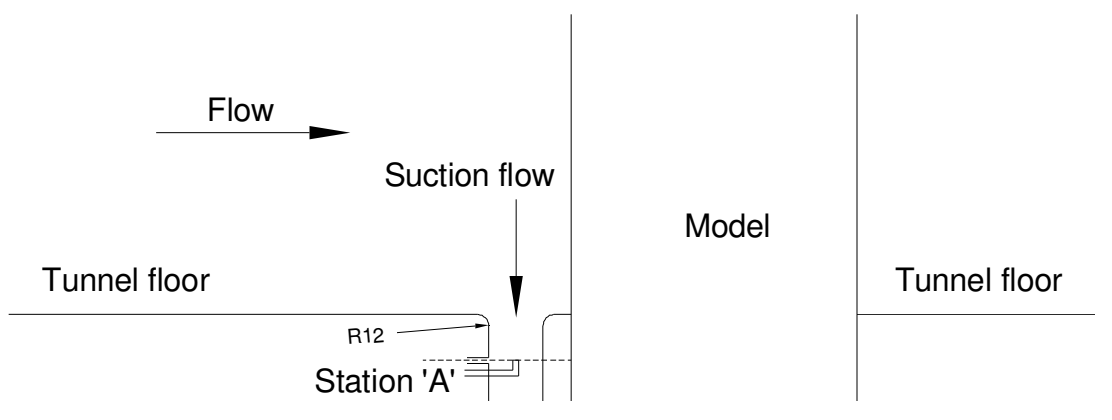

Fig. 7. Suction hole arrangement

It was decided to have suction through a $57 \mathrm{~mm}$ diameter hole with $12 \mathrm{~mm}$ fillets at the inlet. In the empty tunnel, removal of the boundary layer over the suction hole diameter required a suction volume flow rate $(\mathrm{Q})$ of 0.072 $\mathrm{m}^{3} / \mathrm{s}$ at $20 \mathrm{~m} / \mathrm{s}$.

The size of the suction hole was a compromise between some contradicting requirements; limited capability of the suction fan and movement of the saddle point with incidence pushed towards a large size of hole. On the other hand, the disadvantage of a bigger hole was the potential of a larger disturbance in the flow field. The fillet radius was selected to give a minimum pressure loss at the inlet. In Philips ${ }^{6}$ experiment, the ratio of the slot width to 
maximum model thickness was 1.07. A slightly greater ratio, i.e. 1.4 was used for the hole diameter in the current experiment. The hole was located as close to the model as physically possible which resulted in the hole centre located at $60.7 \mathrm{~mm}$ upstream of the model leading edge. Arrangement of the installed suction system is shown in Fig. 8.

Before installation of the suction system in the test section of the wind tunnel the volume flow rate in the duct was calibrated against the dynamic pressure at the centre of the duct at 'Station A' (shown in Fig. 7), which was located $83 \mathrm{~mm}$ downstream of the intake. The calibration was needed so the suction rate could be adjusted during the wind tunnel experiment and set using the core dynamic pressure. Volume flow rate calculated through the pipework is represented as a fraction of the boundary layer volume flow rate $(\mathrm{Q})$ in the following sections.

\section{Testing with Localized Suction}

A photograph of the model in the wind tunnel test section with the suction hole in the tunnel floor is shown in Fig. 9. The suction hole was put in place by a plate which was bolted on the floor. During the tests, edges between the plate and the turntable were taped to get a smooth upstream reflection plane. Air removed from the test section by the suction system was exhausted well away from the balance to avoid undue influence on balance readings. At maximum suction (3.78 times the volume flow rate of the boundary layer) $0.56 \%$ of the wind tunnel air flow was removed.

The measurements were carried out for nine different suction volume flow rates between 0.48Q to 3.78Q. Balance measurements for lift, drag and pitching moment coefficient are shown in Fig. 10 to Fig. 13 together with the results for two no suction cases. For clarity, measurements for some of the suction rates have been omitted in the following figures. The no suction (hole taped) corresponds to the datum half model configuration. The no suction (hole open) case shows the influence of having the suction system installed, but not operating. Full span data was not available at this Reynolds number, but it was anticipated that the deficiencies in the half model data would be similar to those seen in Fig. 4 to Fig. 6 .

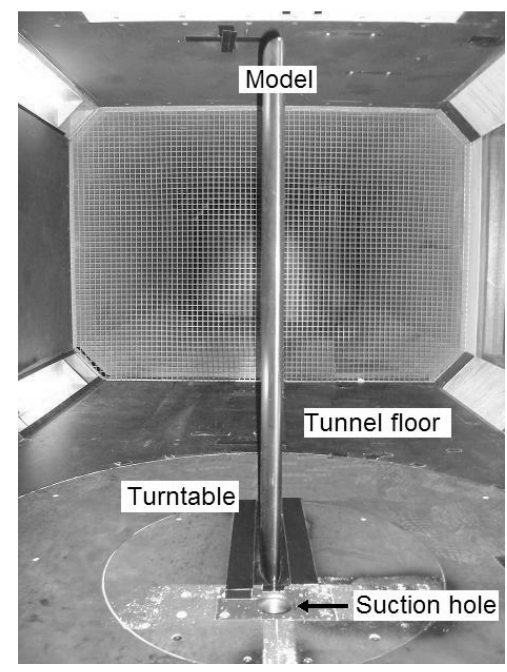

Fig. 9. Model and suction hole arrangementView from upstream

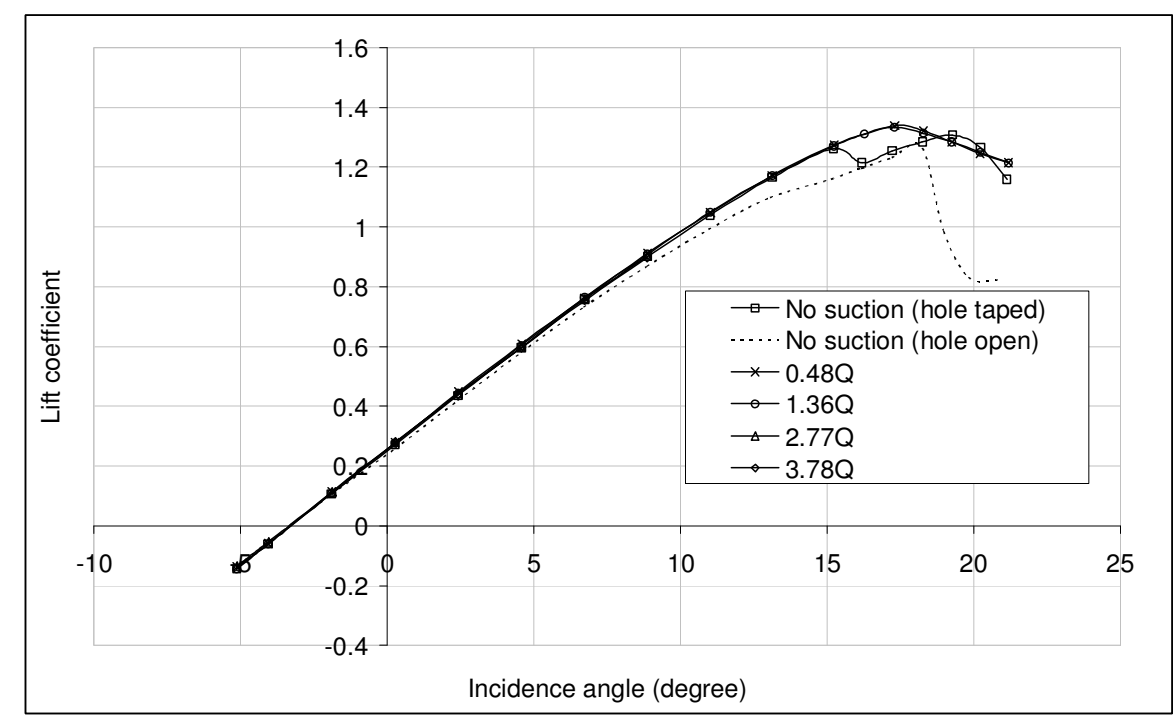

Fig. 10. Lift coefficient for half model, Reynolds number - $0.44 \times 10^{6}$ 


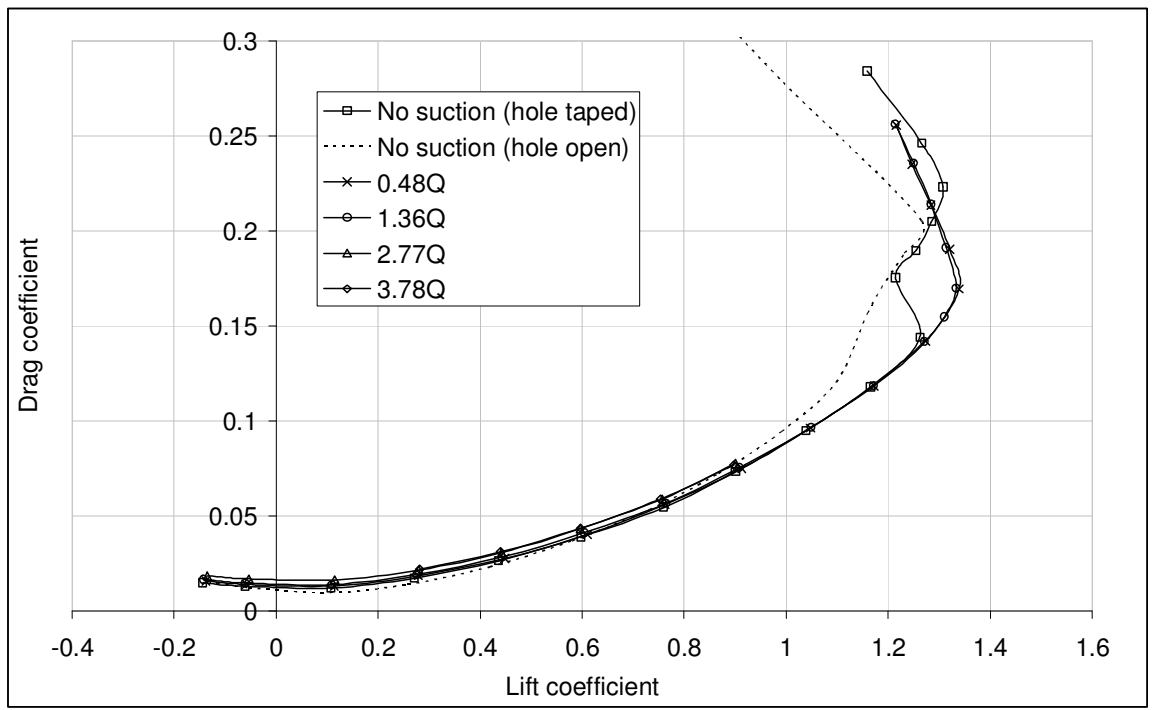

Fig. 11. Drag coefficient for half model, Reynolds number $-0.44 \times 10^{6}$

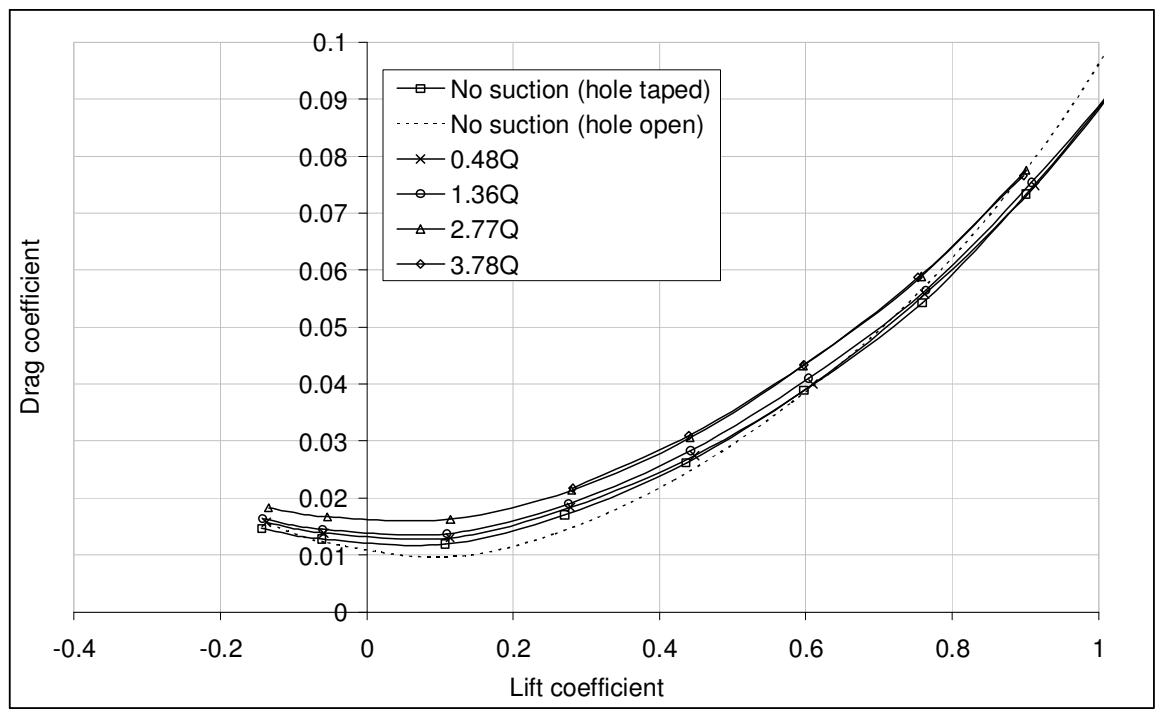

Fig. 12. Drag coefficient for half model (exploded view),

Reynolds number $-0.44 \times 10^{6}$

American Institute of Aeronautics and Astronautics 


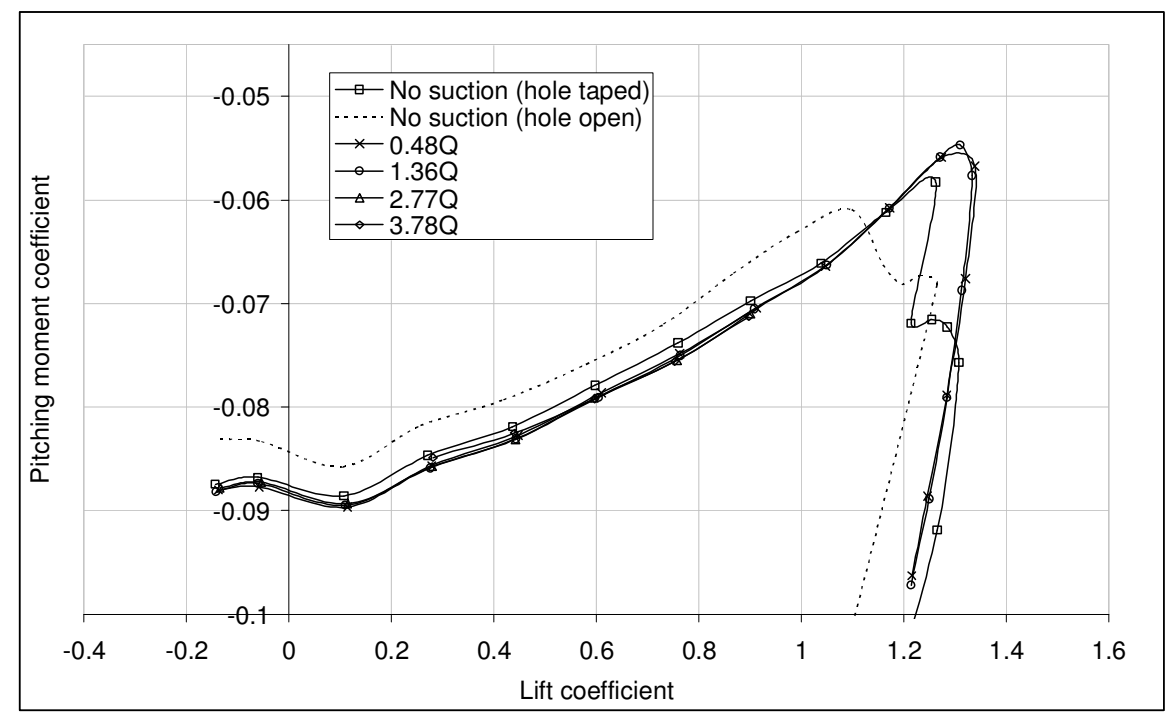

Fig. 13. Pitching moment coefficient for half model, Reynolds number $-0.44 \times 10^{6}$

None of the anticipated improvements in lift curve slope and drag coefficients were seen by applying suction. The lift curve slope was only marginally affected by suction (Fig. 10), although suction did increase the maximum lift coefficient and stall angle. No significant difference was seen in the lift characteristics with increasing suction rates. Around stall, suction delayed the drag rise, but again there was no significant difference with changing suction rate (Fig 11). Below stall, the drag coefficient increased with increasing suction although the increases were smaller at higher lift values (Fig. 11 and Fig. 12). Pitching moment coefficient moved in the right direction i.e. increased nose down when applying suction (Fig. 13) but again the effects were only significant close to stall, and appeared to be largely independent of suction rate.

Surface flow visualization tests using a mixture of titanium dioxide, paraffin and linseed oil were done to investigate the effects of suction seen from balance measurements. The tests were done for no suction (hole taped) and with $1.36 \mathrm{Q}$ suction rate and at a Reynolds numbers of $0.44 \times 10^{6}$. Fig. 14 shows the flow patterns in the junction regions and on the model surface without suction for 4 degrees incidence. In Fig. 14a and Fig. 14b there is no evidence of a horseshoe vortex. A conical flow separation region on the floor and the model upper surface exists (Fig. 14c). On the lower surface a laminar separation is seen, which is modified in the lower $75 \mathrm{~mm}$ of the wing floor junction (Fig. 14d). This modified span is approximately equal to the boundary layer thickness ( $70 \mathrm{~mm}$ to 75 $\mathrm{mm})$ at the model location in the empty tunnel.

For 10 degrees (not shown) and above there was clear evidence of a dividing streamline which indicates the presence of the horseshoe vortex. Fig. 15 shows the flow visualization without suction at 15 degrees. A dividing streamline, which is more prominent on the lower side (Fig 15b), exists around the model. A significant large area of flow separation exists on the floor between the model and the separation line (Fig. 15a). This is same conical separation seen at 4 degree and has grown in size with increasing incidence. At 15 degree it originates at the model leading edge and extends in conical shape covering a distance of about $110 \mathrm{~mm}$ and $228 \mathrm{~mm}$ on the floor and the model, respectively. No such separation was seen on the lower surface (Fig. 15b and Fig. 15d). 


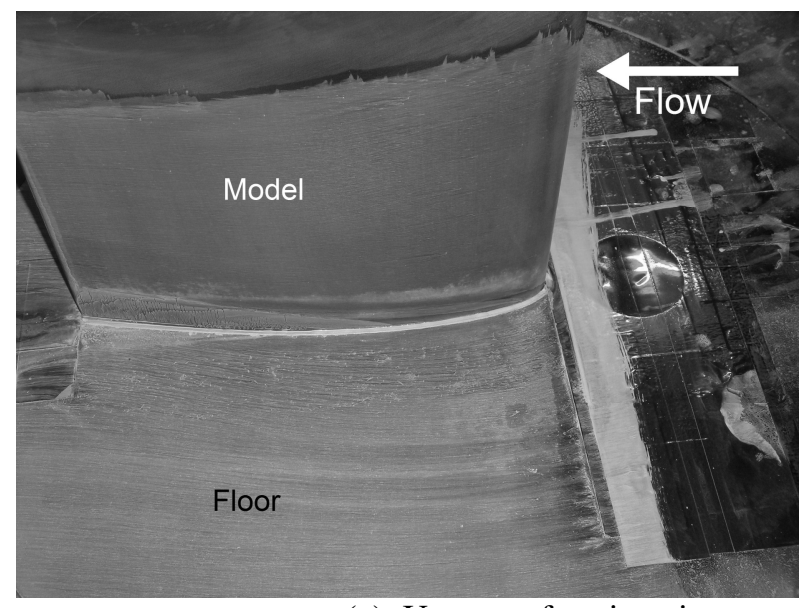

(a): Upper surface-junction

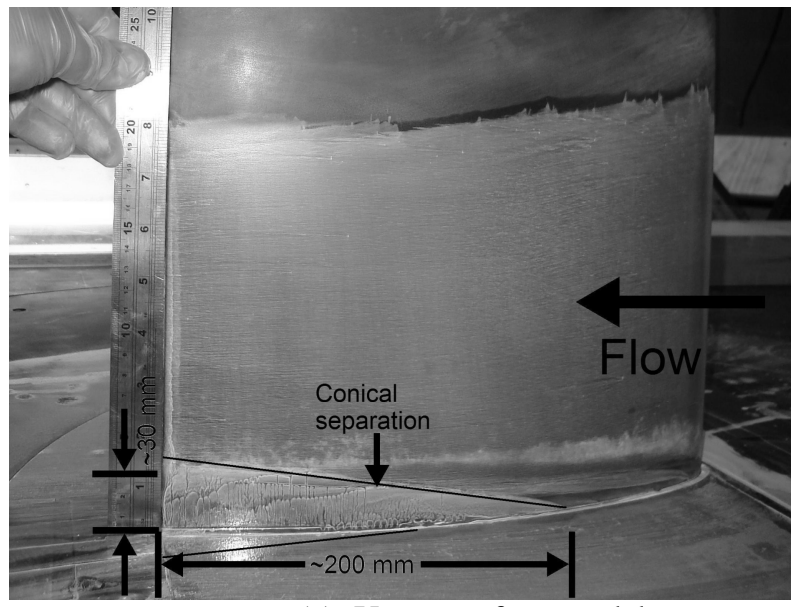

(c): Upper surface-model

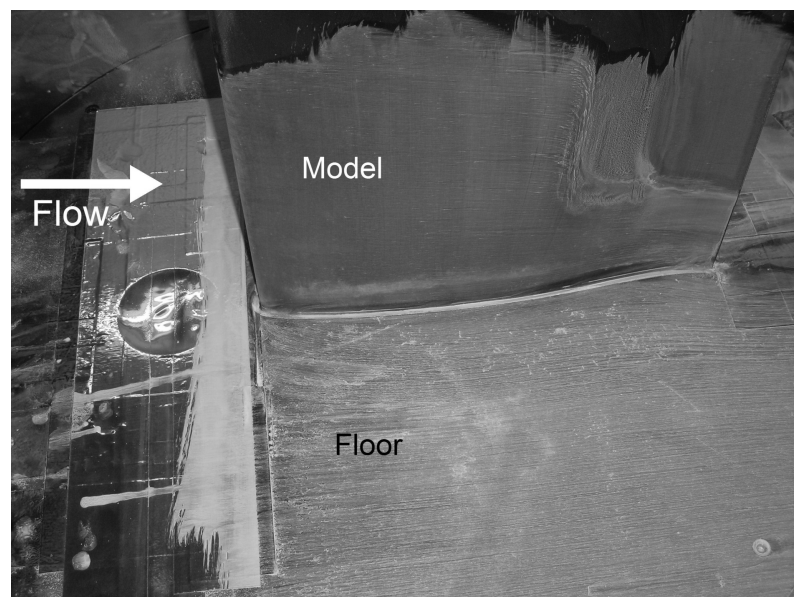

(b): Lower surface-junction

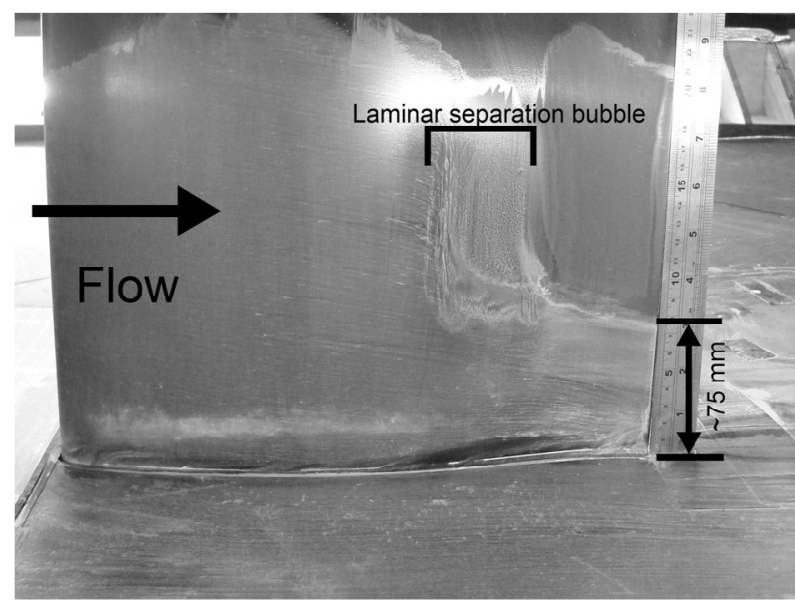

(d): Lower surface-model

Fig. 14. Junction flow patterns at 4.0 degrees incidence without suction

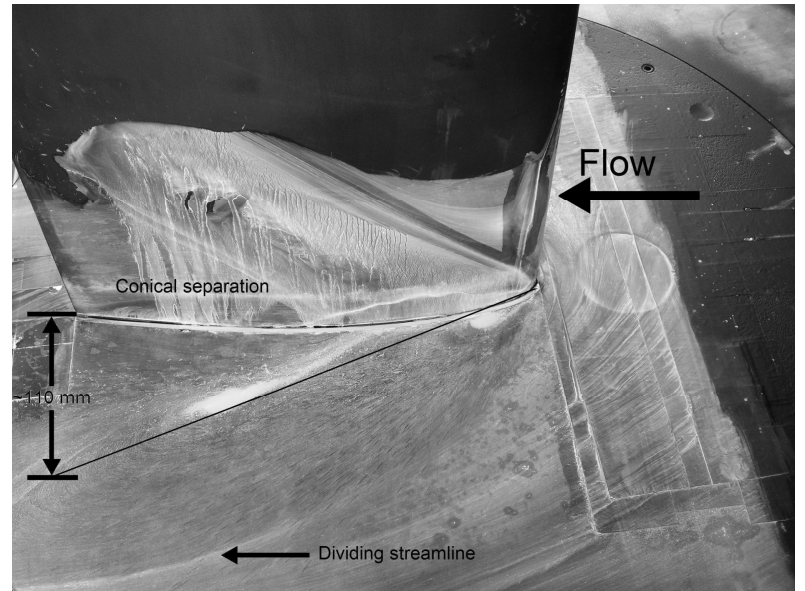

(a): Upper surface-junction

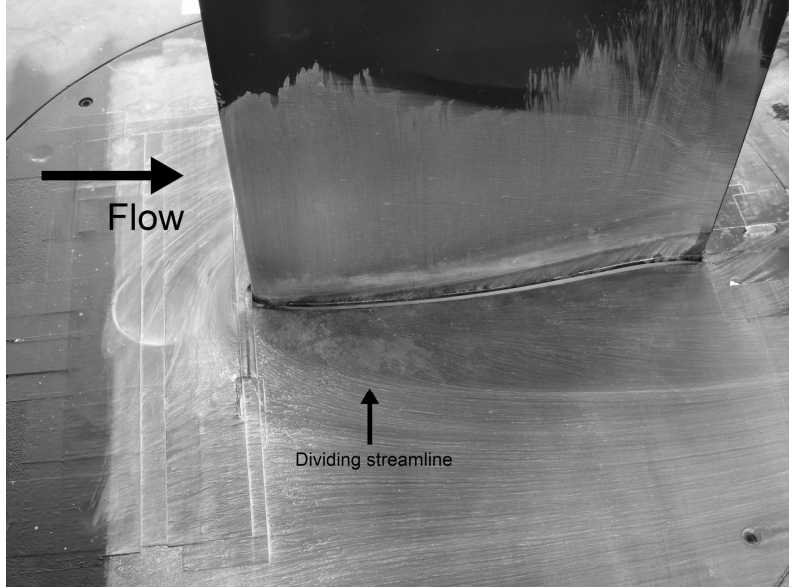

(b): Lower surface-junction 


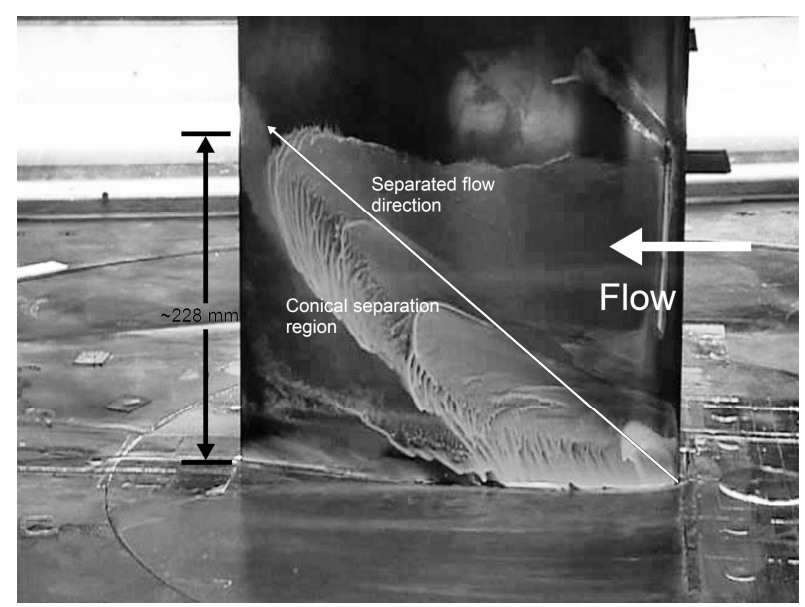

(c): Upper surface-model

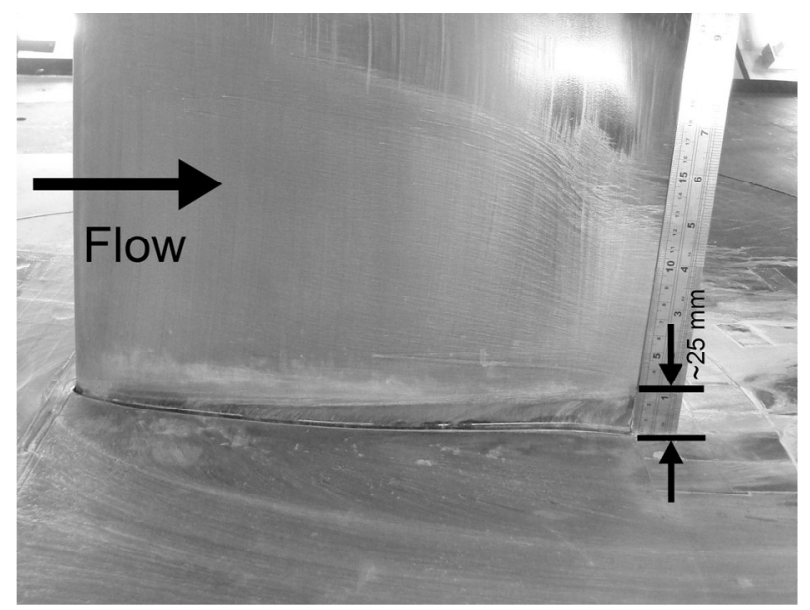

(d): Lower surface-model

Fig. 15: Flow patterns at 15.0 degrees incidence without suction

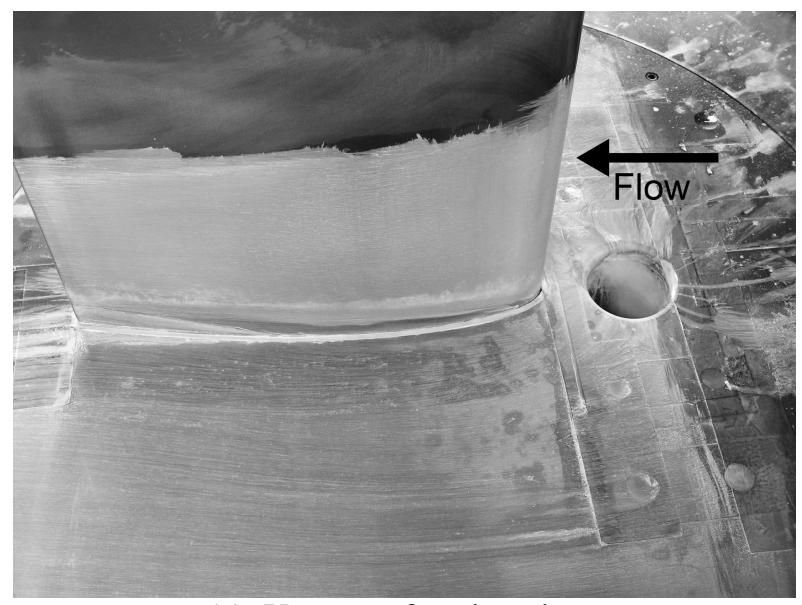

(a): Upper surface-junction

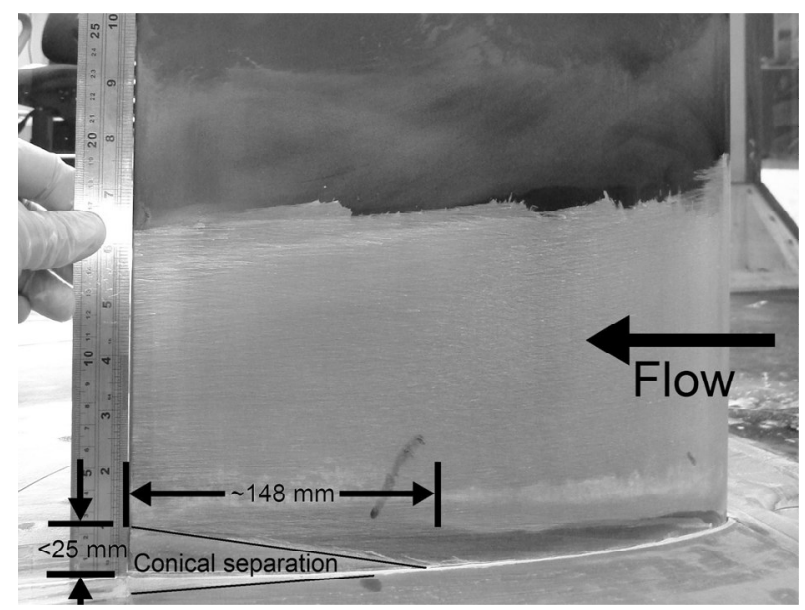

(c): Upper surface-model

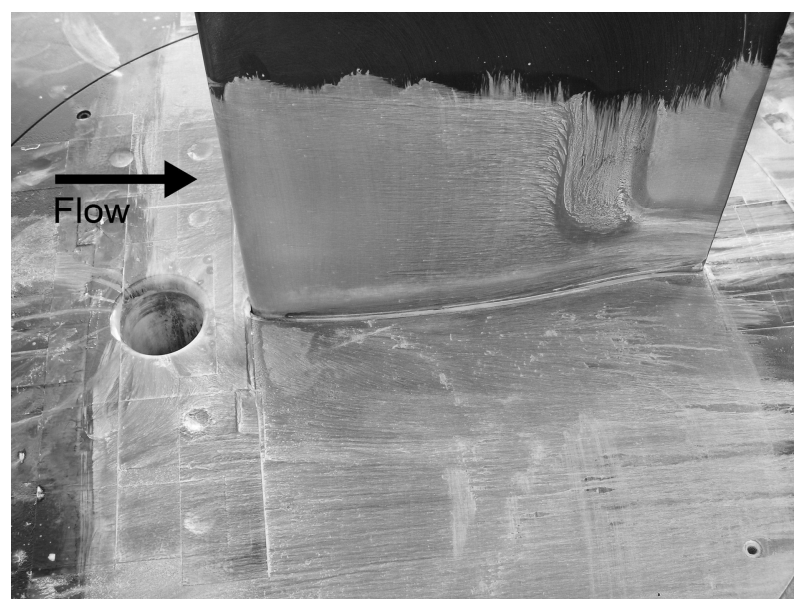

(b): Lower surface-junction

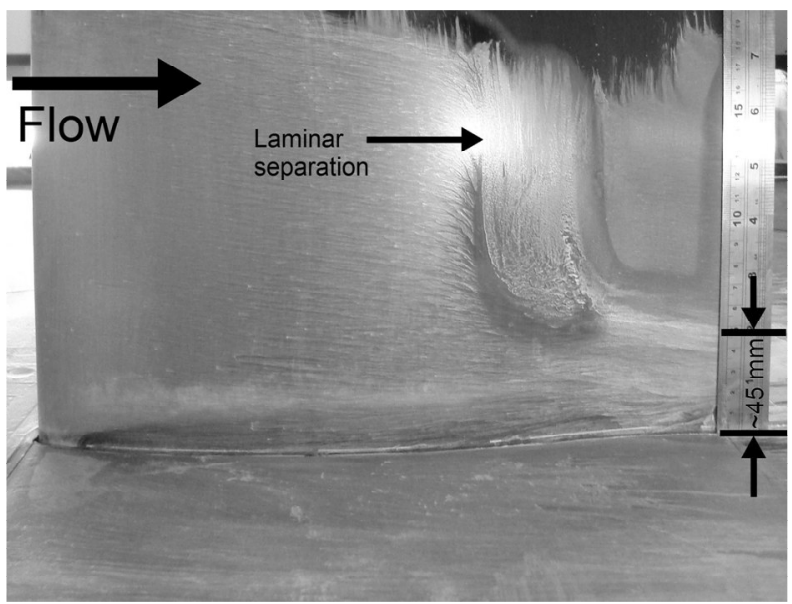

(d): Lower surface-model

Fig. 16: Junction flow patterns at 4.0 degrees incidence with 1.36Q suction 
The lack of a significant horseshoe vortex at 4 degrees meant that suction had little influence on the junction flow, and this was confirmed by flow visualization tests with suction (Fig. 16) which can be compared with Fig. 14. The only effect of the suction at low incidences is seen as a slight modification to the upper surface conical separation and the lower surface laminar separation areas. At four degrees, upper surface separation region on the floor reduced from $200 \mathrm{~mm}$ to $148 \mathrm{~mm}$ and from $30 \mathrm{~mm}$ to under $25 \mathrm{~mm}$ on the model. The span of the laminar separation on the lower had increased and extended closer to the reflection plane Overall suction did modify the spanwise flow but according to the balance measurements, the modifications were not significant.

At 15 degrees suction eliminated the dividing streamline from the upper surface side along with significant reduction of separation (comparing Fig. 15 and Fig. 17) The separation region has a similar conical shape as without suction; however the size was greatly reduced form $110 \mathrm{~mm}$ to $25 \mathrm{~mm}$ on the floor (comparing Fig. 15a and Fig. 17a) and from $228 \mathrm{~mm}$ to $50 \mathrm{~mm}$ on the model (comparing Fig. 15c and Fig. 17c). These significant reductions in the separation area on the model surface are believed to be the cause of the increased stall angle with suction. On the lower surface side the dividing streamline moved further away from the model and the horseshoe vortex still existed and so was not completely eliminated by the use of suction.

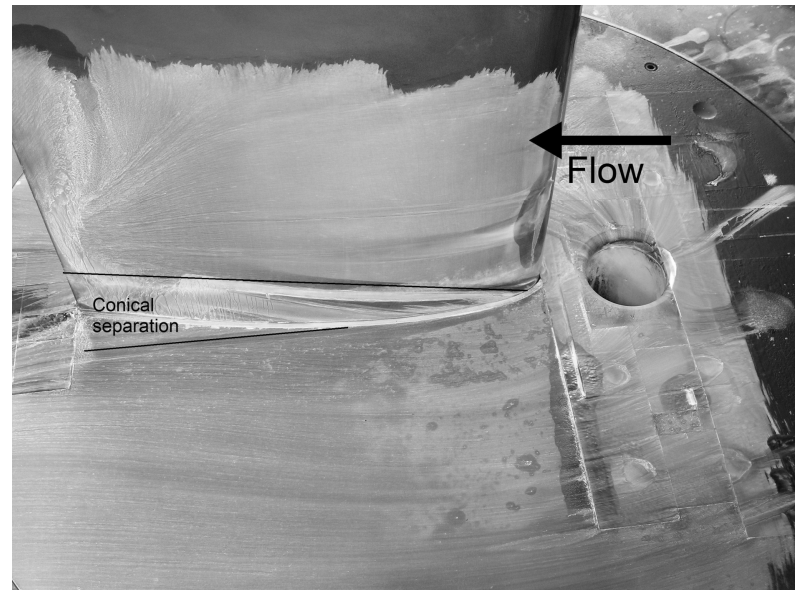

(a): Upper surface-junction

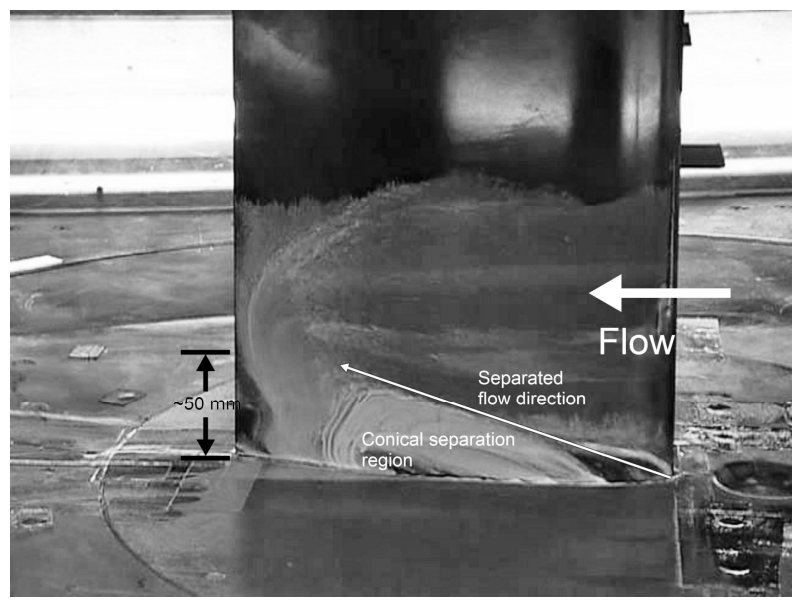

(c): Upper surface-model

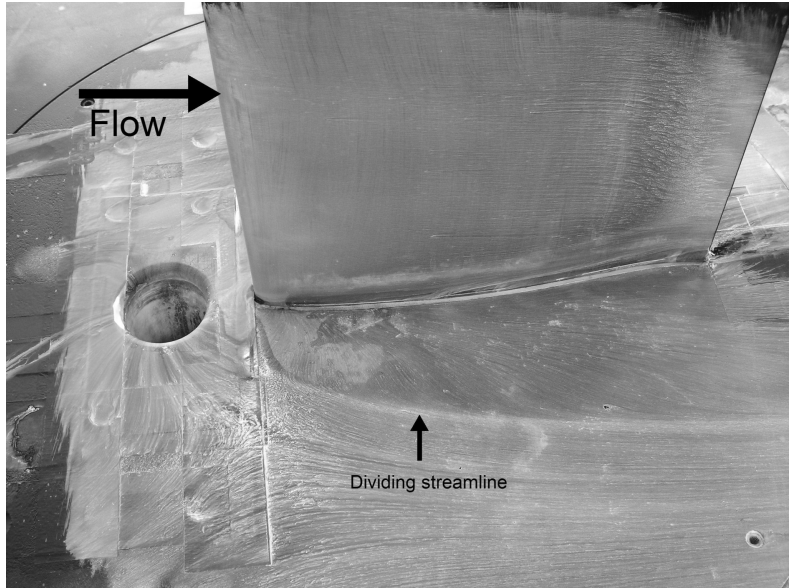

(b): Lower surface-junction

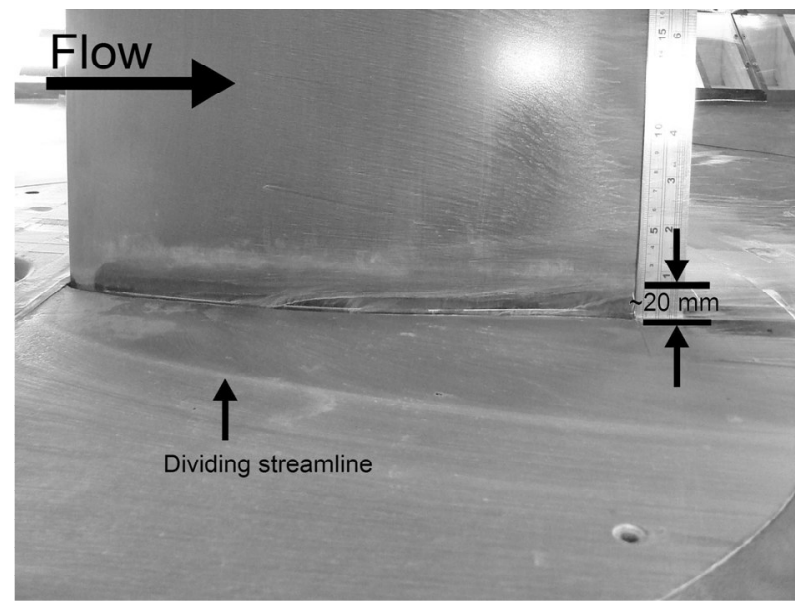

(d): Lower surface-model

Fig. 17: Junction flow patterns at 15.0 degrees incidence with 1.36Q suction

Balance measurements suggested that low suction rates were as effective as high suction rates in modifying stall behavior. The use of a lower suction rate meant that the fan could be used at higher wind tunnel speeds. Further tests were carried out to investigate the effect of suction near stall at a higher Reynolds number. These tests were done at 
the maximum possible Reynolds number $\left(0.88 \times 10^{6}\right)$ at which stall characteristics could be measured, and were not limited by the balance capabilities.

Measurements at Reynolds number of $0.88 \times 10^{6}$ are shown in Fig. 18 to Fig. 20. It should be noted that 'Q' has been changed to $0.11 \mathrm{~m}^{3} / \mathrm{s}$ due to the different boundary layer thickness and tunnel speed. Suction did not increase the stall angle of attack and also the drag remained unaffected. Pitching moment coefficient became more nose down by applying suction below the stall angle of attack. The advantage of localized suction appears to be that the unrepresentative early stall of a half model at low Reynolds number is removed.

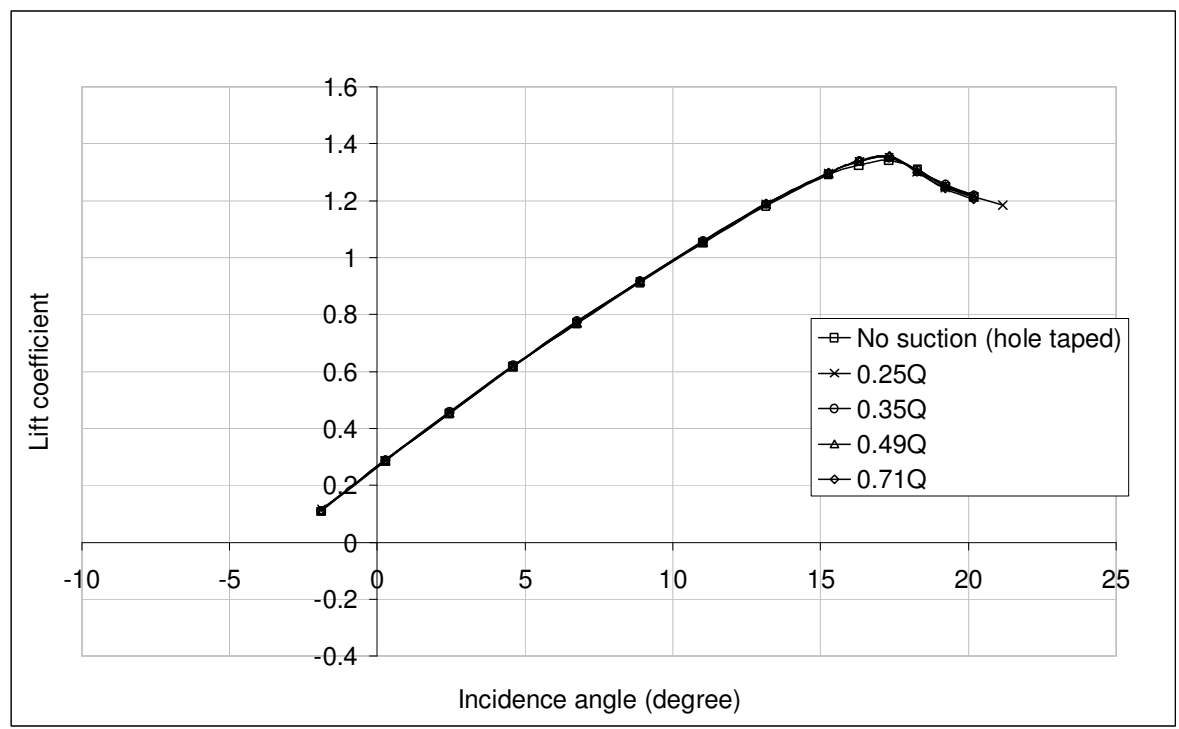

Fig. 18. Lift coefficient for half model, Reynolds number $-0.88 \times 10^{6}$

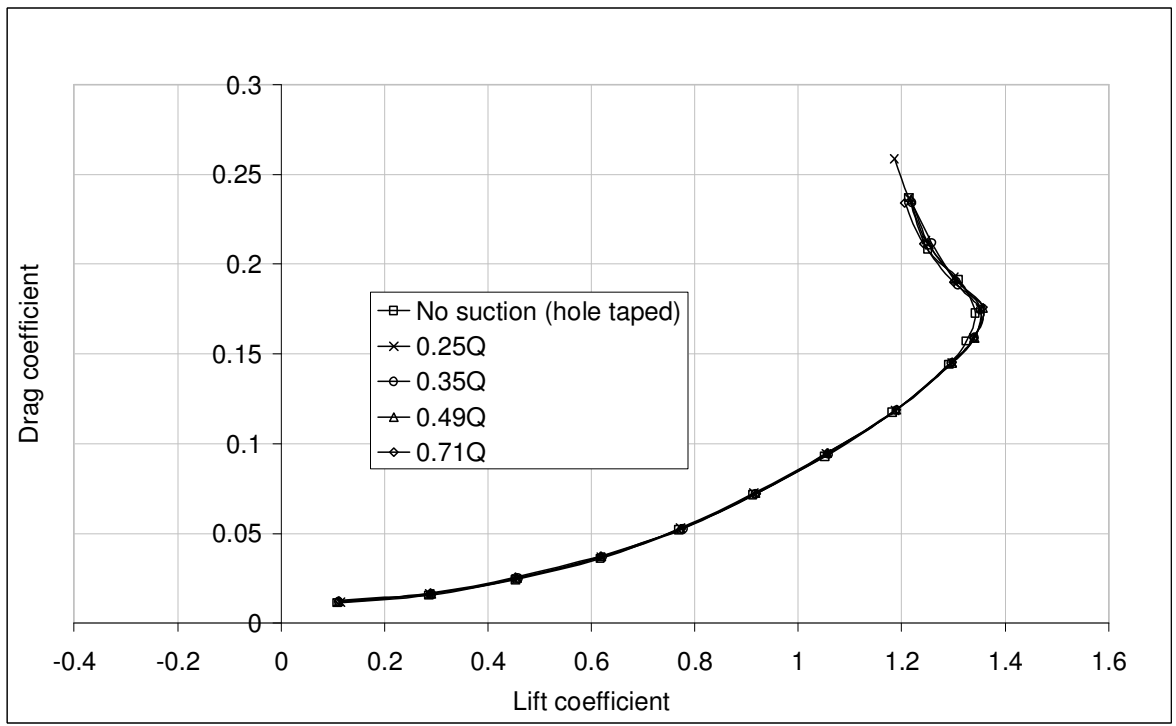

Fig. 19. Drag coefficient for half model, Reynolds number $-0.88 \times 10^{6}$

12

American Institute of Aeronautics and Astronautics 


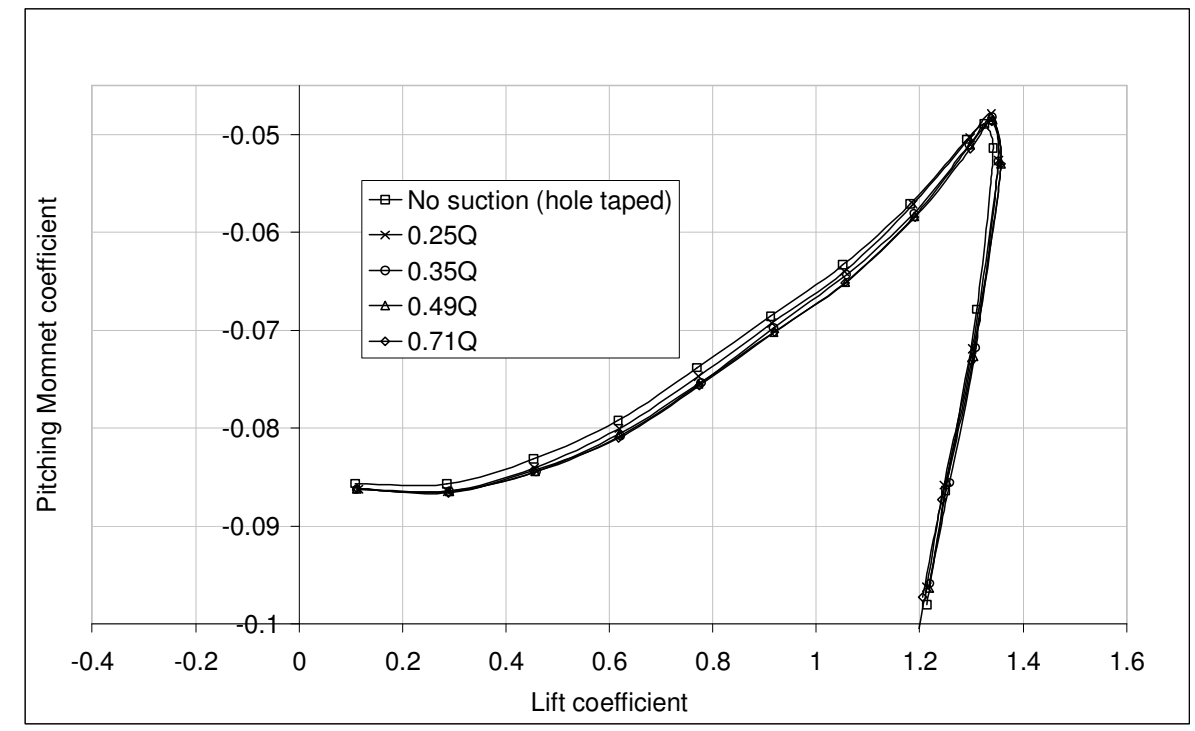

Fig. 20. Pitching Moment coefficient for half model, Reynolds number $-0.88 \times 10^{6}$

\section{Conclusion}

The following are concluded based on the present study:

1 There is little evidence to suggest that suction prior to the leading edge can produce a significant improvement in the aerodynamic characteristics of half models. This may be due to the absence of a horseshoe vortex over much of the incidence range for this particular model.

2 Junction effects are more pronounced at low Reynolds number and it appears that so is the effectiveness of suction. Suction can improve the aerodynamic characteristics of a half model near stall. The improvement is due to elimination of a significant large flow separation on the model upper surface once suction is applied.

\section{References}

1. Pope, A. \& Harper, J.J., (1966), "Low speed wind tunnel testing", John Wiley \& Sons INC., New York.

2. Goodson, K.W. \& King, T.J., (1949), "Longitudinal Stability and control characteristics of a semi span wind tunnel model of a tailless airplane and a comparison with complete model wind tunnel tests and semi span wing flow tests", NASA RM L9C31.

3. Bliek, J.A., (March 1959), "Notes on Half model testing in wind tunnels", AGARD Report 298.

4. Earnshaw, P.B., Green , A.R. \& Jelly, A.H., "A study of the use of half models in high lift wind tunnel testing," AGARDCP-515, October 1992, pp., 20.1- 20.9.

5. Bippes, H. \& Turk, M., (1982), "Half model testing applied to wings above and below stall", Recent contributions to Fluid Mechanics, pp. 22-30, Berlin, Heidelberg, New York: Springer.

6. Philips, D.B., Cimbala, J.M. \& Treaster, A.L. (1992), "Suppression of the wing-body junction vortex surface suction", Journal of aircraft, vol. 29, no. 1, January - February 1992, pp. 118 - 122.

7. Barberis, D., Molton, P. \& Malaterre, T., (1998), "Control of 3D turbulent boundary layer separation caused by a wing body junction”, Experimental thermal and fluid sciences, vol. 16, pp. 54-63. 
8. Johnson, M.J., Ravindra, K. \& Andres, R., (1994), "Comparative study of the elimination of the wing fuselage junction vortex by boundary layer suction and blowing", Reno, Nevada, 32nd Aerospace Sciences Meeting \& Exhibit, January 10-13, 1994, AIAA, Reston, No. 94-0293.

9. Gaugler, R.E. \& Russell, L.M., (1982), "Flow visualization study of the horseshoe vortex in a turbine stator cascade", NACA Technical Paper 1884.

10. Eckerle, W.A. \& Langston, L.S., (1986), "Measurement of a turbulent horseshoe vortex formed around a cylinder", NASA CR-3986.

11. Johnston, J.P., (September 1960), "The turbulent boundary layer at a plane of symmetry in a three dimensional flow", Journal of Basic Engineering, vol. 82, pp. 622-628.

12. Johl, G., Passmore, M. \& Render, P., (2004), "Design methodology and performance of an indraft wind tunnel", The aeronautical Journal, vol. 108, no. 1087, pp. 465-474.

13. Herriot, J.G., (1950), "Blockage corrections for three dimensional flow closed throat wind tunnels with considerations of the effect of compressibility", NACA report 995.

14. ESDU 95014, (October 1995), "Upwash interference for wings in solid-liner wind tunnels using subsonic linearized-theory", ESDU.

15. McGhee, R.J. \& Beasley, W.D., (1977), "Low speed wind tunnel results for a modified 13\% thick airfoil”, NACA Technical Memorandum-X-74018.

16. Anderson, R.F, (1936), "Determination of the characteristics of tapered wings", NACA report 572. 